\title{
Human genetics of the Kula Ring: Y-chromosome and mitochondrial DNA variation in the Massim of Papua New Guinea
}

\author{
Mannis van Oven ${ }^{1}$, Silke Brauer ${ }^{2,5}$, Ying Choi $^{1}$, Joe Ensing ${ }^{3}$, Wulf Schiefenhövel ${ }^{4}$, Mark Stoneking ${ }^{\star, 2}$ \\ and Manfred Kayser ${ }^{\star}, 1$
}

The island region at the southeastern-most tip of New Guinea and its inhabitants known as Massim are well known for a unique traditional inter-island trading system, called Kula or Kula Ring. To characterize the Massim genetically, and to evaluate the influence of the Kula Ring on patterns of human genetic variation, we analyzed paternally inherited Y-chromosome (NRY) and maternally inherited mitochondrial (mt) DNA polymorphisms in $>400$ individuals from this region. We found that the nearly exclusively Austronesian-speaking Massim people harbor genetic ancestry components of both Asian (AS) and Near Oceanian (NO) origin, with a proportionally larger NO NRY component versus a larger AS mtDNA component. This is similar to previous observations in other Austronesian-speaking populations from Near and Remote Oceania and suggests sex-biased genetic admixture between Asians and Near Oceanians before the occupation of Remote Oceania, in line with the Slow Boat from Asia hypothesis on the expansion of Austronesians into the Pacific. Contrary to linguistic expectations, Rossel Islanders, the only Papuan speakers of the Massim, showed a lower amount of NO genetic ancestry than their Austronesian-speaking Massim neighbors. For the islands traditionally involved in the Kula Ring, a significant correlation between inter-island travelling distances and genetic distances was observed for mtDNA, but not for NRY, suggesting more male- than female-mediated gene flow. As traditionally only males take part in the Kula voyages, this finding may indicate a genetic signature of the Kula Ring, serving as another example of how cultural tradition has shaped human genetic diversity.

European Journal of Human Genetics (2014) 22, 1393-1403; doi:10.1038/ejhg.2014.38; published online 12 March 2014

\section{INTRODUCTION}

Oceania represents a vast geographic area with a complex human settlement history. ${ }^{1,2}$ Previous studies have addressed human genetic variation in Oceania, particularly Polynesia, ${ }^{3-8}$ mainland New Guinea $^{9-13}$ and Island Melanesia. ${ }^{14-18}$ One area of Near Oceania (NO) yet understudied from a human genetic perspective is the island region off the southeastern tip of New Guinea (Figure 1). Administratively designated the Milne Bay Province of Papua New Guinea (PNG), this area encompasses the D'Entrecasteaux Islands (ie, Normanby, Fergusson, Dobu and Goodenough), the Trobriand Islands, the Woodlark group (ie, Gawa, Woodlark and the Laughlan Islands), the Louisiade Archipelago (ie, Misima, Sudest, Rossel and the islands of the Calvados chain), as well as a portion of the nearby PNG mainland. The inhabitants of this region have been designated as Massim, ${ }^{19-21}$ a term that has since been used to refer not only to the people but also to the geocultural region inhabited by them. ${ }^{22}$ From the many islands of the Massim, only the Trobriand Islands were included in previous human genetic studies ${ }^{4,7,11,16,23}$ Hence, a human genetic description of the Massim is lacking so far, despite the major attention they have received in the cultural anthropology literature, in particular with respect to the Kula, a traditional inter-island trading system described in more detail below.

Human settlement of mainland New Guinea goes back at least 40-50 thousand years: the Ivane Valley in eastern PNG was occupied 43-49 thousand years ago (kya). ${ }^{24}$ The Solomon Islands (ie, the archipelago east of the Milne Bay area) were occupied by at least 28 kya. ${ }^{25}$ Archeological findings in the Massim are scant ${ }^{26}$ and there is currently no evidence of long-term human occupation before 2 kya. ${ }^{27,28}$ Given the lower sea levels during the Pleistocene, many of the current Massim islands may have been connected by land bridges, ${ }^{29}$ potentially facilitating human migration between them. The languages spoken in the Massim belong to the Papuan Tip cluster within the Western Oceanic branch of the Austronesian language family, ${ }^{30}$ with the exception of Rossel Island, the easternmost island of the Louisiade Archipelago, where a non-Austronesian (Papuan) language is spoken. ${ }^{31}$

Among a number of the islands in the Milne Bay Province an extensive trading system, referred to as Kula or Kula Ring has traditionally developed. ${ }^{32-37}$ This Kula exchange system was extensively described by anthropologist Bronislaw Malinowski in his

${ }^{1}$ Department of Forensic Molecular Biology, Erasmus MC University Medical Center Rotterdam, Rotterdam, The Netherlands; ${ }^{2}$ Department of Evolutionary Genetics, Max Planck Institute for Evolutionary Anthropology, Leipzig, Germany; ${ }^{3}$ Missionaries of the Sacred Heart (MSC), St. Paul's Pastoral Centre, Hagita, Alotau, Papua New Guinea; ${ }^{4}$ Human Ethology Group, Max Planck Institute for Ornithology, Andechs, Germany

${ }^{5}$ Current address: Netherlands Forensic Institute, The Hague, The Netherlands.

${ }^{*}$ Correspondence: Professor M Kayser, Department of Forensic Molecular Biology, Erasmus MC University Medical Center Rotterdam, 3000 CA Rotterdam, The Netherlands. Tel: + 3110 7038073; Fax: + 3110 7044575; E-mail: m.kayser@erasmusmc.nl

or Professor M Stoneking, Department of Evolutionary Genetics, Max Planck Institute for Evolutionary Anthropology, D-04103 Leipzig, Germany. Tel: +49 3413550502 ; Fax: +49 341 3550555; E-mail: stoneking@eva.mpg.de

Received 1 November 2013; revised 6 February 2014; accepted 13 February 2014; published online 12 March 2014 


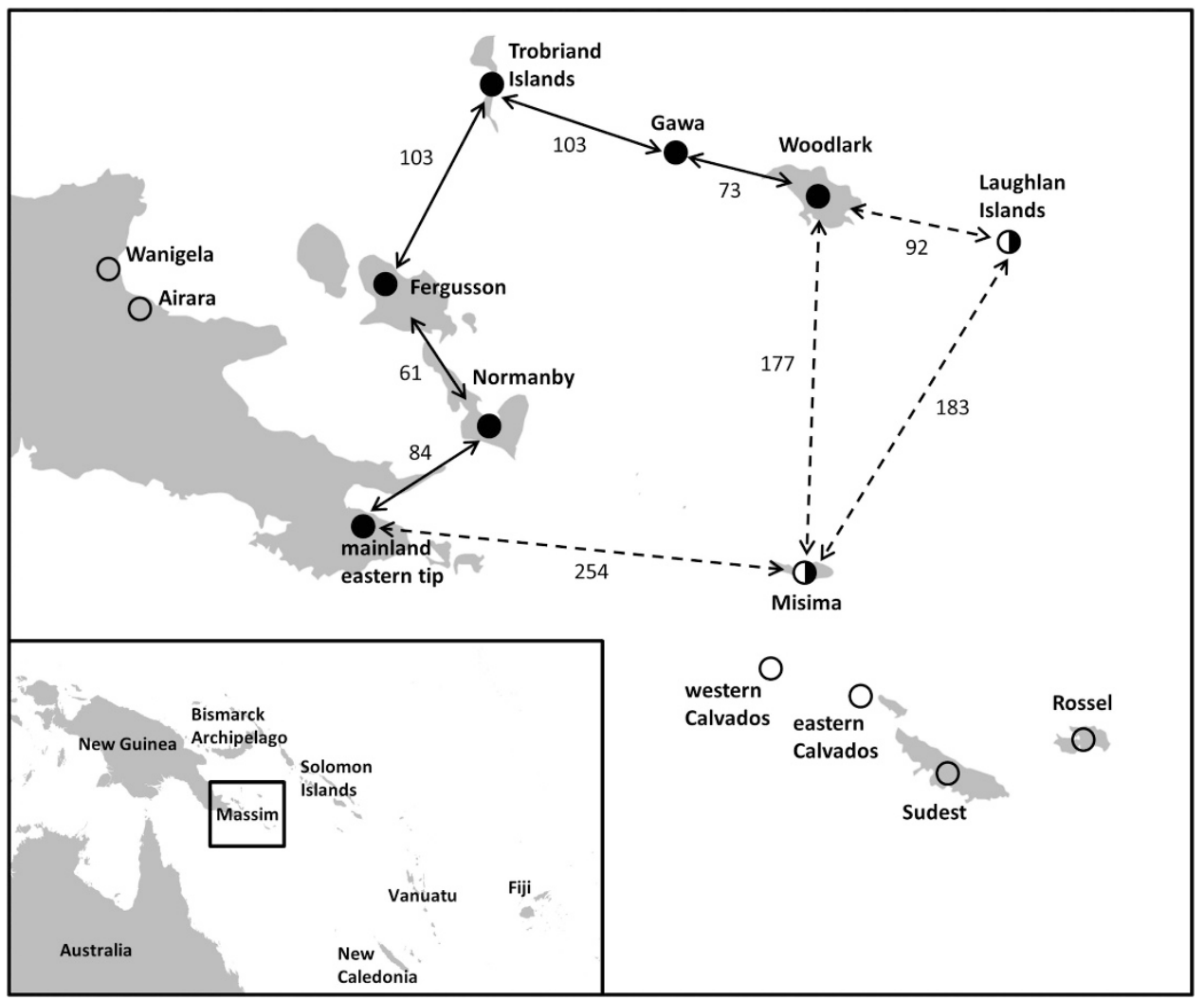

Figure 1 Map of the Massim area within Oceania depicting the locations of the 14 groups studied. Groups that participate in the Kula traditional trading system are indicated with filled black dots, whereas groups that do not are indicated with open dots; groups marginally involved in the Kula are indicated with half-filled dots. Arrows indicate trading interactions between Kula partners with approximate travelling distances given in $\mathrm{km}$.

classic work 'Argonauts of the western Pacific'33 and has since become an oft-cited anthropological example of balanced reciprocity. This particular trading system assures that items only available on some islands, for instance, because of unequal geographic distribution of natural resources, but vitally needed on other islands, are shared among people from different islands. The Kula is centered around the exchange of two valuables in a ring-like manner: necklaces, called soulava, are moved in clockwise direction through the island world, whereas armshells, called mwali, do so in the opposite direction (Figure 1). Notably, only men participate in the Kula; they sail to fixed trading partners on other Kula islands and it is not uncommon for them to stay away from home for several months. The islands of the southeastern Massim are not extensively involved in the Kula. Only Misima is sometimes mentioned as a Kula partner, but trading with Misima is probably much less intense as compared with the northern and western Massim. ${ }^{35,38}$

The presence of the Kula trading system, involving regular migrations between islands with lengthy stays away from home, raises the question whether besides the economic exchange also genetic exchange takes place. If the male-specific migration of the Kula indeed left detectable signatures in the genomes of the contemporary populations from the region, this should be evident by studying the paternally inherited non-recombining portion of the Y-chromosome (NRY), in comparison with the maternally inherited mitochondrial (mt) DNA. If true, the Kula would serve as another example of the impact of human culture on genetic variation as has been observed before, for example, for residence patterns ${ }^{39}$ and social stratification. ${ }^{40}$ Furthermore, it is of interest to investigate to what extent the inhabitants of Rossel Island, given that they are the only
non-Austronesian (ie, Papuan) speakers of the Massim, differ genetically from the other, Austronesian-speaking people of the Massim, in particular their direct neighbors from Sudest. Although human contacts between Rossel and Sudest certainly existedgeographic distance between the two islands is small and sea-crossing from one to the other is feasible-the Rossel society has been described as endogamous, ${ }^{41}$ suggesting limited or no genetic exchange with Sudest, a situation that could have promoted genetic divergence between the two populations.

With these questions in mind, we analyzed NRY and mtDNA polymorphisms in individuals from across the Massim area (Figure 1). In reconstructing the demographic history of Oceania, our results not only fill an important gap between previous genetic studies on the mainland of New Guinea in the west, ${ }^{9-13}$ the Bismarck Archipelago in the north ${ }^{14-16}$ and the Solomon Islands in the east, ${ }^{17,18}$ but also provide further insights into how human culture impacts on human genetics.

\section{MATERIALS AND METHODS}

\section{Samples}

The sampling consisted of over 400 individuals from various locations within the Milne Bay Province, PNG, as well as from two nearby coastal communities from Collingwood Bay, Oro Province, PNG (Figure 1). Samples were collected in 2001 (by MK, JE and WS) under approval of the Medical Board of PNG and with support from the Diocese of Alotau, PNG (Missionaries of the Sacred Heart, MSC), particularly then Bishop Desmond Moore MSC. Volunteers, with individual written informed consent, provided a saliva sample and were asked to give information regarding the origins of their parents and grandparents. Genetic work carried out within this study was additionally approved 
by the Ethics Commission of the University of Leipzig Medical Faculty and the Medical Ethics Committee of the Erasmus MC University Medical Center Rotterdam.

Each sample was assigned to one of the following 14 population groups according to their matrilineal (maternal grandmother's or mother's) geographic origin for mtDNA analyses, and male samples according to their patrilineal (paternal grandfather's or father's) geographic origin for NRY analyses: (1) Trobriand Islands; (2) Gawa; (3) Woodlark (also known as Muyuw); (4) Laughlan Islands (also known as Budibudi Islands); (5) Fergusson (also known as Moratau), including a few individuals from nearby Dobu (also known as Watoa) and Goodenough (also known as Nidula); (6) Normanby (also known as Duau); (7) Milne Bay mainland eastern tip; (8) Misima, including some individuals from nearby Paneati, Panapompom and Kimuta; (9) western Calvados Chain (including: Motorina, Bagaman, Utian or Brooker Island, and Panaumala); (10) eastern Calvados Chain (including: Dadahai, Kuanak or Abaga Gaheia Island, Nimoa, Panatinane or Joannet Island, Panawina, Sabarl, and Wanim or Grass Island); (11) Sudest (also known as Vanatinai or Tagula); (12) Rossel (also known as Yela); (13) Wanigela and nearby settlements; and (14) Airara and nearby settlements. In case two sampled individuals were closely related in the male and/or female line (by sharing the same father/paternal grandfather and/or mother/maternal grandmother), one of them was excluded from the NRY and/or mtDNA data set, respectively. The Trobriand Islands group was supplemented with the Trobriand samples described in previous studies. ${ }^{7,16,18}$ The final Massim set comprised 389 individuals for NRY analyses and 432 individuals for mtDNA analyses.

For comparisons in a wider geographic context, we included previously described population data from East Asia, Island Southeast Asia, and Near and Remote Oceania, using a minimal sample size of 20 individuals per population for both NRY and mtDNA ${ }^{7,10,16,18,42,43}$ (for an overview, see Supplementary Table S1).

\section{Genotyping}

DNA was extracted from cheek swabs via a previously described salting-out protocol. ${ }^{44}$ Haplogroup-defining single-nucleotide polymorphisms on the non-recombining part of the Y-chromosome (Y-SNPs) were typed by multiplex genotyping assays (details available in Supplementary Table S2) based on the single-base primer extension principle (SNaPshot; Applied Biosystems, Foster City, CA, USA). NRY short tandem repeats (Y-STRs) were genotyped with the AmpFISTR Yfiler Kit (Applied Biosystems) following the manufacturer's recommendations. The first hypervariable segment (HVS-I; sequence range: nps 16024-16392) of the mtDNA genome was sequenced as described previously. ${ }^{7}$ Presence of the mtDNA 9-bp deletion (m.8281_8289del), characteristic for haplogroup B, was determined by PCR as described elsewhere. ${ }^{7}$ Samples for which the mtDNA haplogroup could not be unambiguously deduced from combined HVS-I and 9-bp deletion data, were SNaPshot genotyped for additional, haplogroup-defining mtDNA polymorphisms by applying the multiplex SNP assays described in Ballantyne et al. ${ }^{45}$ The 432 HVS-I sequences of the Massim samples reported in this study have been deposited in NCBI GenBank under accession numbers KF034102-KF034533.

\section{Data analysis}

NRY haplogroups were assigned based on the classification tree provided in Supplementary Table S3, following Karafet et al. ${ }^{46}$ (with the exception of the placement of marker M83). MtDNA haplogroups were inferred according to the classification tree provided in Supplementary Table S4, following Build 15 of the mtDNA phylogeny available at http://www.phylotree.org. ${ }^{47}$ For analyses at the mtDNA HVS-I level, nps 16180-16183 were disregarded because $\mathrm{A}$ to $\mathrm{C}$ transversions at these positions are dependent on the presence of m.16189T $>$ C. For analyses at the Y-STR level, the following 10 loci were used: DYS19, DYS389I, DYS390, DYS391, DYS392, DYS393, DYS437, DYS438, DYS448 and Y-GATA-H4, following van Oven et al. ${ }^{43}$ Measures of genetic diversity, genetic distance $\left(F_{\mathrm{ST}} / R_{\mathrm{ST}} / \Phi_{\mathrm{ST}}\right)$, analysis of molecular variance (AMOVA) and Mantel tests were calculated using Arlequin version 3.5 (Excoffier and Lischer ${ }^{48}$ ). Multidimensional scaling (MDS) plots were generated using the PROXSCAL algorithm ${ }^{49}$ implemented in SPSS version 20 (IBM, Armonk, NY, USA). Median-joining haplotype networks ${ }^{50}$ were constructed using the software Network version 4.6.1.0 (Fluxus Technology Ltd, Clare, Suffolk, UK), applying equal weighting for mtDNA sites and the following weighting scheme for Y-STR loci: DYS19 (3), DYS389I (3), DYS390 (3), DYS391 (3), DYS392 (6), DYS393 (4), DYS437 (4), DYS438 (6), DYS448 (4) and Y-GATA-H4 (3).

Table 1 Observed NRY haplogroup frequencies (\%) in the Massim area

\begin{tabular}{|c|c|c|c|c|c|c|c|c|c|c|c|c|c|c|}
\hline Population & $n$ & $C-R P S 4 Y^{* a}$ & $C-M 208^{* a}$ & $K-M 9^{\star a}$ & $M-M 4^{* a}$ & $M-P 34^{* a}$ & $M-M 104^{* a}$ & $M-P 117^{a}$ & $S-M 230^{* a}$ & $S-M 254^{* a}$ & $O-M 119 * b$ & $O-M 110^{b}$ & $O-M 122 * b$ & $O-M 324 * b$ \\
\hline \multicolumn{15}{|c|}{ Collingwood Bay } \\
\hline WAN & 21 & & 9.5 & & & 90.5 & & & & & & & & \\
\hline \multicolumn{15}{|c|}{ Western Massim } \\
\hline FER & 35 & & 17.1 & 37.1 & & 17.1 & & 2.9 & & 2.9 & 17.1 & 5.7 & & \\
\hline \multicolumn{15}{|c|}{ Northern Massim } \\
\hline TRO & 60 & & 10.0 & 25.0 & 1.7 & 26.7 & & & & & 11.7 & 16.7 & & 8.3 \\
\hline GAW & 10 & & & 20.0 & & 20.0 & & & & & & 10.0 & 10.0 & 40.0 \\
\hline WOO & 13 & & 7.7 & 38.5 & & & & & & & 7.7 & 30.8 & & 15.4 \\
\hline LAU & 5 & & 20.0 & 40.0 & & 20.0 & & & & & & & & 20.0 \\
\hline \multicolumn{15}{|c|}{ Southeastern Massim } \\
\hline WCA & 19 & & 26.3 & 42.1 & & & & & & 5.3 & 5.3 & 10.5 & & 10.5 \\
\hline ECA & 11 & & 36.4 & 36.4 & & & & & & 18.2 & 9.1 & & & \\
\hline SUD & 38 & & 36.8 & 39.5 & & 2.6 & & & & 15.8 & 2.6 & 2.6 & & \\
\hline ROS & 80 & & & 33.8 & & 6.3 & & & & 30.0 & 1.3 & 28.8 & & \\
\hline
\end{tabular}

Abbreviations: AIR, Airara; ECA, eastern Calvados; FER, Fergusson; GAW, Gawa; LAU, Laughlan Islands; MET, mainland eastern tip; MIS, Misima; NOR, Normanby; ROS, Rossel; SUD, Sudest; TRO, Trobriand Islands; WAN, Wanigela; WCA, western Calvados; WOO, Woodlark.

${ }^{a}$ Assigned a Near Oceanian origin following Kayser $\mathrm{M}^{2}$ and Kayser et al, 7,16

bAssigned an Asian origin following Kayser $\mathrm{M}^{2}$ and Kayser et al. ${ }^{7,16}$ 

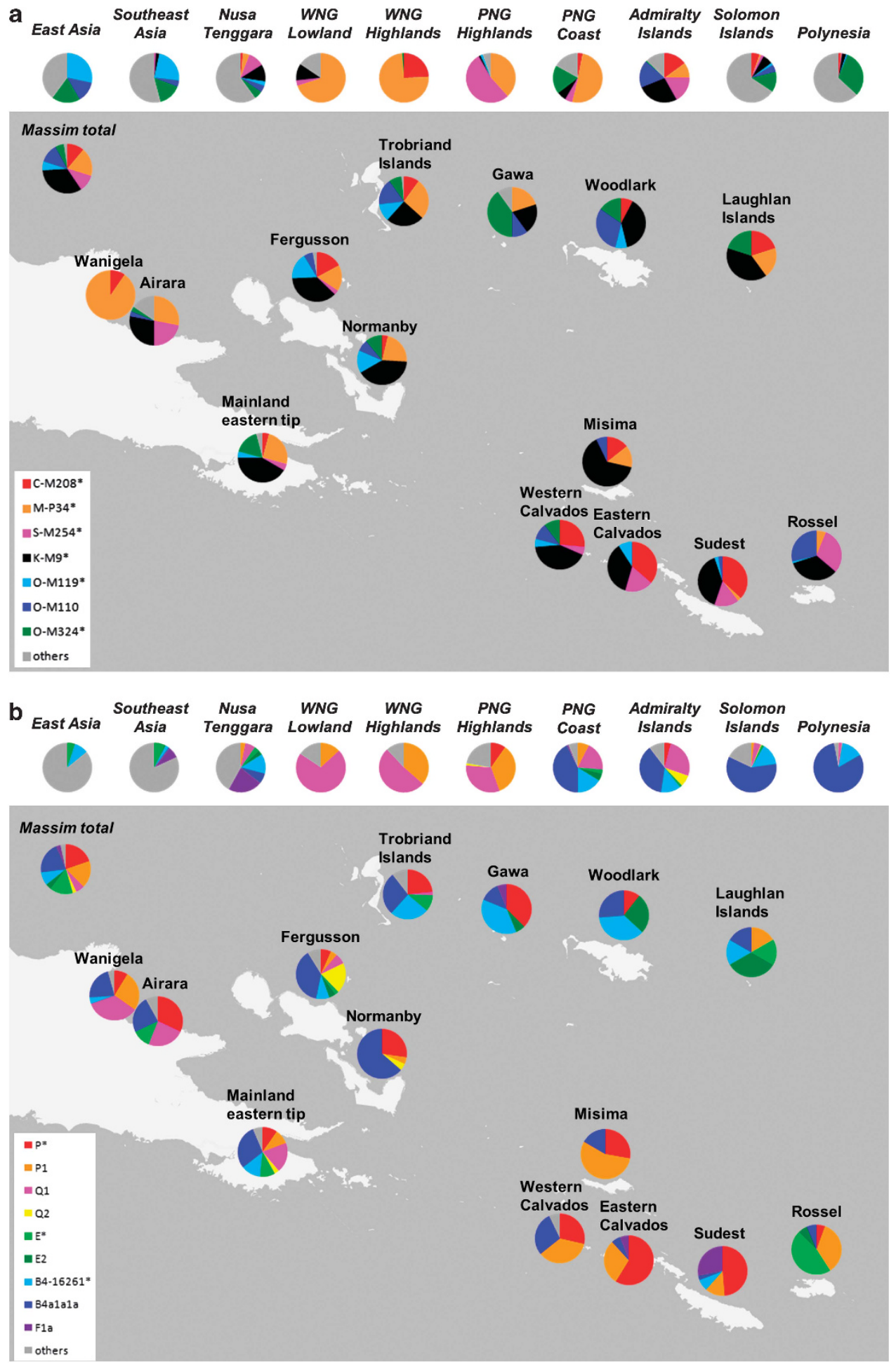

Figure 2 Geographic distribution of (a) the seven major Y-chromosome haplogroups and (b) the nine major mtDNA haplogroups observed in the Massim area (see Tables 1 and 2 for complete haplogroup frequency data). For comparison, the gross frequencies of these haplogroups as observed in other regions of Asia/Oceania, pooled from different population samples, are included as well using previously published data.7,10,16,18,42 For practical reasons, the PNG Highlands group includes Kapuna, a Papuan-speaking group from the Gulf Province of PNG with an assumed origin in the highlands, while the PNG Coast group includes Bereina, an Austronesian-speaking group from the southern coastal area of PNG.

\section{RESULTS AND DISCUSSION}

\section{NRY and mtDNA haplogroups in the Massim}

In total, $13 \mathrm{NRY}$ haplo-/paragroups were detected, all falling within the major clades $\mathrm{C}, \mathrm{M}, \mathrm{S}, \mathrm{O}$ and $\mathrm{K}^{\star}$ (Table 1 ). In particular, seven haplo-/paragroups encompass the bulk (97.7\%) of NRY diversity (Figure 2a). Y-haplogroups O-M119*(xM110), O-M110 and $\mathrm{O}-\mathrm{M} 324^{*}(\mathrm{xM} 7, \mathrm{M} 134)$ are of Asian/Austronesian (AS) origin, whereas haplogroups C-M208*(xP33,P54), M-P34*(xM83) and S-M254*(xM226) 
Table 2 Observed mtDNA haplogroup frequencies (\%) in the Massim area

\begin{tabular}{|c|c|c|c|c|c|c|c|c|c|c|c|c|c|c|}
\hline Population & $n$ & $Q^{* a}$ & $Q 1^{a}$ & $Q 2^{a}$ & $P^{* a}$ & $P 1^{a}$ & $B 4^{* b}$ & $B 4-16261^{\star b}$ & $B 4 a 1 a 1 a^{b}$ & $B 5 b^{b}$ & $F 1 a^{b}$ & $E^{\star b}$ & $E 2^{b}$ & $R 23^{b}$ \\
\hline \multicolumn{15}{|l|}{ Collingwood Bay } \\
\hline Wanigela & 23 & 4.3 & 34.8 & & 8.7 & 26.1 & & 4.3 & 21.7 & & & & & \\
\hline Airara & 25 & 4.0 & 24.0 & & 32.0 & & & & 24.0 & 4.0 & & 12.0 & & \\
\hline \multicolumn{15}{|l|}{ Western Massim } \\
\hline Fergusson & 45 & 6.7 & 6.7 & 20.0 & 6.7 & 4.4 & & 8.9 & 37.8 & 2.2 & & 2.2 & 4.4 & \\
\hline Normanby & 22 & & & 4.5 & 27.3 & 4.5 & & & 63.6 & & & & & \\
\hline Mainland eastern tip & 31 & 3.2 & 19.4 & 3.2 & 9.7 & 9.7 & & 12.9 & 29.0 & 3.2 & & 9.7 & & \\
\hline \multicolumn{15}{|l|}{ Northern Massim } \\
\hline Trobriand Islands & 47 & 6.4 & 2.1 & & 23.4 & & 4.3 & 25.5 & 27.7 & & & 10.6 & & \\
\hline Gawa & 16 & & & & 37.5 & & & 37.5 & 12.5 & & 6.3 & & 6.3 & \\
\hline Woodlark & 19 & & & & 10.5 & & & 36.8 & 26.3 & & & & 26.3 & \\
\hline Laughlan Islands & 6 & & & & & 16.7 & & 16.7 & 16.7 & & & 16.7 & 33.3 & \\
\hline \multicolumn{15}{|l|}{ Southeastern Massim } \\
\hline Misima & 18 & & & & 27.8 & 55.6 & & & 16.7 & & & & & \\
\hline Western Calvados & 14 & & & & 28.6 & 35.7 & & & 28.6 & & & & & 7.1 \\
\hline Eastern Calvados & 17 & & & & 58.8 & 29.4 & & & 5.9 & & 5.9 & & & \\
\hline Sudest & 39 & & & & 48.7 & 12.8 & & 7.7 & 2.6 & & 28.2 & & & \\
\hline Rossel & 110 & & & & 5.5 & 35.5 & & & 6.4 & & & 46.4 & 6.4 & \\
\hline
\end{tabular}

assigned a Near Oceanian origin following Kayser $\mathrm{M}^{2}$ and Friedlaender et al. ${ }^{57}$

${ }^{b}$ Assigned an Asian origin following Kayser $\mathrm{M}^{2}$; Friedlaender et al ${ }^{51}$; Trejaut et al ${ }^{52}$; Soares et al ${ }^{56}$; Hill et al ${ }^{58}$ and Peng et al. ${ }^{59}$

are of NO origin, as previously described. ${ }^{7,16}$ The K-M9* (xP79,M4,M353,P117,M214,M74,M230) paragroup is particularly frequent in the Massim (overall: $33.4 \%$ ) and probably includes several yet undefined sublineages of K-M9. A Y-STR haplotype network analysis for K-M9* (Supplementary Figure S1) indeed showed that its haplotypes are quite diverse. Given that K-M9* was not found in East Asia and only sporadically in Southeast Asia in our data set, whereas it is rather frequent in parts of NO such as in the Admiralty Islands (27.0\%), a NO origin for the Massim K-M9* Y-chromosomes observed here seems most likely. NRY haplogroups were not homogeneously distributed throughout the Massim (Figure 2a). The NO haplogroup $\mathrm{M}-\mathrm{P} 34^{*}$ and the AS haplogroup O-M $324^{\star}$ were more prominent in the northern and western Massim, whereas the NO haplogroup S-M254* was more frequent in the southeastern Massim. Furthermore, Rossel stood out from its local neighbors because of its high frequency of AS haplogroup O-M110 and complete absence of NO haplogroup C-M208*. The Wanigela group from the Collingwood Bay showed a remarkably low haplogroup diversity (Supplementary Table S5) with over $90 \%$ belonging to M-P34*.

We distinguished 12 different mtDNA haplo-/paragroups in the Massim, all falling within the mtDNA clades P, Q, E, B4, B5, F and R23 (Table 2). In particular, nine haplo-/paragroups accounted for $96.5 \%$ of the mtDNA pool (Figure 2b). Haplogroups F1a, B4-16261*(xB4alala) and B4alala (also known as the 'Polynesian motif') are of (ultimate) AS origin, ${ }^{51,52}$ although B4alala may also have originated in descendants of East Asians residing in Nusa Tenggara ${ }^{53-55}$ or in the Bismarck Archipelago. ${ }^{8}$ Haplogroups $\mathrm{E}^{*}(\mathrm{xE} 2)$ and E2 are likely of Taiwanese/Island Southeast AS origin ${ }^{56}$ (here also classified as AS), whereas haplogroups $\mathrm{P}^{\star}(\mathrm{xP} 1), \mathrm{P} 1, \mathrm{Q} 1$ and Q2 have a NO origin. ${ }^{57}$ Like the NRY haplogroups, also the mtDNA haplogroups were not homogeneously distributed throughout the Massim (Figure 2b). NO haplogroup P1 was much more frequent in the southeastern Massim, while AS haplogroup B4-16261* was almost absent there, and NO haplogroups Q1 and Q2 were almost only found in the western Massim. Rossel again stood out from its local neighbors, because of its major component of AS haplogroup $\mathrm{E}^{\star}$ and low frequency of NO haplogroup $\mathrm{P}^{\star}$. Interestingly, Sudest showed a relatively high frequency of the AS haplogroup F1a, which was otherwise only detected sporadically (single individuals) in the eastern Calvados and in Gawa but not in any of the other Massim groups studied. The presence of haplogroup R23 in a single individual from the western Calvados was unexpected, as this haplogroup has so far only been observed much more westward in Nusa Tenggara ${ }^{58}$ and among Cham from Vietnam. ${ }^{59}$

\section{AS versus NO genetic ancestry in the Massim}

To quantify the relative contributions of NO versus AS paternal and maternal ancestors to the gene pool of the Massim people, we assigned, based on previous knowledge, the most probable ancestral origin to each of the observed NRY and mtDNA haplogroups (Table 3). Overall, the proportion of AS mtDNA haplogroups in the Massim (52.3\%) was more than two times higher than that of AS NRY haplogroups (23.9\%). Such an excess of AS mtDNAs compared with AS Y-chromosomes was previously also observed in Admiralty Islanders north of the PNG mainland $(60.7 \%$ AS mtDNA versus $18.2 \%$ AS NRY), ${ }^{16}$ in Solomon Islanders (excluding Polynesian outliers; $77.7 \%$ AS mtDNA versus $27.5 \%$ AS NRY $)^{18}$ and in Polynesians from Remote Oceania (96.4\% AS mtDNA versus $34.6 \%$ AS NRY). ${ }^{7,16}$ This pattern is consistent with a historical admixture scenario that involved mainly AS women and mainly NO men in NO, perhaps the Bismarck Archipelago, before the occupation of Remote Oceania, in line with the previously suggested Slow Boat from Asia hypothesis of Polynesian origin in particular and the Austronesian origin in general. ${ }^{4,7,16,60}$ Within the Massim, the people from the northern islands carried the highest amount of AS ancestry, while relatively low amounts of AS ancestry were seen in the southeastern Massim. However, the non-Austronesian-speaking Rossel Islanders 
Table 3 NO versus AS ancestry proportions, based on NRY and mtDNA haplogroup origins and composition, in the Massim area and in regional reference populations

\begin{tabular}{|c|c|c|c|c|c|c|c|c|}
\hline \multirow[b]{2}{*}{ Population } & \multicolumn{4}{|c|}{ NRY haplogroups } & \multicolumn{4}{|c|}{ MtDNA haplogroups } \\
\hline & $n$ & NO ancestry (\%) & AS ancestry (\%) & Unknown ancestry (\%) & $n$ & NO ancestry (\%) & AS ancestry (\%) & Unknown ancestry (\%) \\
\hline \multicolumn{9}{|l|}{ Collingwood Bay } \\
\hline Wanigela & 21 & 100.0 & - & - & 23 & 73.9 & 26.1 & - \\
\hline Airara & 32 & 93.8 & 6.3 & - & 25 & 60.0 & 40.0 & - \\
\hline \multicolumn{9}{|l|}{ Western Massim } \\
\hline Fergusson & 35 & 77.1 & 22.9 & - & 45 & 44.4 & 55.6 & - \\
\hline Normanby & 27 & 66.7 & 33.3 & - & 22 & 36.4 & 63.6 & - \\
\hline Mainland eastern tip & 24 & 79.2 & 20.8 & - & 31 & 45.2 & 54.8 & - \\
\hline \multicolumn{9}{|l|}{ Northern Massim } \\
\hline Trobriand Islands & 60 & 63.3 & 36.7 & - & 47 & 31.9 & 68.1 & - \\
\hline Gawa & 10 & 40.0 & 60.0 & - & 16 & 37.5 & 62.5 & - \\
\hline Woodlark & 13 & 46.2 & 53.8 & - & 19 & 10.5 & 89.5 & - \\
\hline Laughlan Islands & 5 & 80.0 & 20.0 & - & 6 & 16.7 & 83.3 & - \\
\hline \multicolumn{9}{|l|}{ Southeastern Massim } \\
\hline Misima & 14 & 92.9 & 7.1 & - & 18 & 83.3 & 16.7 & - \\
\hline Western Calvados & 19 & 73.7 & 26.3 & - & 14 & 64.3 & 35.7 & - \\
\hline Eastern Calvados & 11 & 90.9 & 9.1 & - & 17 & 88.2 & 11.8 & - \\
\hline Sudest & 38 & 94.7 & 5.3 & - & 39 & 61.5 & 38.5 & - \\
\hline Rossel & 80 & 70.0 & 30.0 & - & 110 & 40.9 & 59.1 & - \\
\hline Total & 389 & 76.1 & 23.9 & - & 432 & 47.7 & 52.3 & - \\
\hline East Asia ${ }^{a}$ & 113 & - & 92.0 & 8.0 & 121 & - & 79.3 & 20.7 \\
\hline Southeast Asia ${ }^{\mathrm{a}}$ & 205 & 9.8 & 82.4 & 7.8 & 199 & - & 80.4 & 19.6 \\
\hline Nusa Tenggara ${ }^{a, b}$ & 373 & 85.5 & 13.7 & 0.8 & 31 & 9.7 & 83.9 & 6.5 \\
\hline WNG Lowland ${ }^{a, c}$ & 90 & 100.0 & - & - & 121 & 84.3 & 3.3 & 12.4 \\
\hline WNG Highlands ${ }^{a, c}$ & 95 & 98.9 & 1.1 & - & 107 & 92.5 & - & 7.5 \\
\hline PNG Highlands ${ }^{a}$ & 73 & 98.6 & 1.4 & - & 72 & 91.7 & 1.4 & 6.9 \\
\hline PNG Coast ${ }^{a}$ & 65 & 81.5 & 18.5 & - & 80 & 32.5 & 67.5 & - \\
\hline Admiralty Islands ${ }^{d}$ & 148 & 81.8 & 18.2 & - & 145 & 37.9 & 60.7 & 1.4 \\
\hline Solomon Islands & 712 & 72.5 & 27.5 & - & 703 & 20.9 & 77.7 & 1.4 \\
\hline Polynesia & 315 & 63.2 & 34.6 & 2.2 & 306 & 3.6 & 96.4 & - \\
\hline
\end{tabular}

Abbreviations: AS, Asian; NO, Near Oceanian.

aKayser et al. ${ }^{7}$

bMona et al. ${ }^{42}$

'Tommaseo-Ponzetta et al. ${ }^{10}$

${ }^{\mathrm{d}}$ Kayser et al. ${ }^{16}$

eDelfin et al. ${ }^{18}$

formed an exception, showing a larger AS proportion both for NRY and mtDNA than their direct Austronesian-speaking neighbors, a finding that contradicts the expectation based on linguistics (for more details on Rossel see below).

\section{Massim genetic population substructure and the Kula}

Genetic distances between the Massim groups calculated from NRY and mtDNA haplogroup/haplotype data (Supplementary Table S6) were visualized in MDS plots (Figure 3). Wanigela appears as a strong outlier in both NRY-based plots, which can be explained by its exceptionally high frequency of haplogroup M-P34* and the complete lack of AS NRY haplogroups. Airara takes an outlier position only in the Y-STR-based plot, but not in the NRY-haplogroup-based plot, which can be explained by the fact that Airara's K-M9* Y-STR haplotypes are quite distinct from the $\mathrm{K}-\mathrm{M} 9^{*}$ haplotypes in other Massim groups (Supplementary Figure S1). In contrast, neither
Wanigela nor Airara are outliers in the mtDNA-based plots. Both groups come from the coast of mainland PNG (Collingwood Bay), on the border with the Massim area, and were included in this study because Goodenough, one of the islands in the western Massim, is visible from Collingwood Bay, and therefore people from Wanigela and Airara may be involved in admixture processes with the Massim. Moreover, archeology has revealed the presence of prehistoric pottery in the Trobriand Islands that originated from the Collingwood Bay ${ }^{61,62}$ (modern pottery in the Trobriands comes mostly from the Amphlett Islands). Nearly all NO haplogroups found in the Massim are also found in the Collingwood Bay, hence our results do not exclude the possibility that the Massim have ancestral ties in the Collingwood Bay, in line with the archeological evidence. However, a pairwise haplotype-sharing analysis (Table 4) did not reveal increased haplotype sharing between the Collingwood groups and the nearest sampled group of Fergusson, nor the Trobriand Islanders, suggesting 

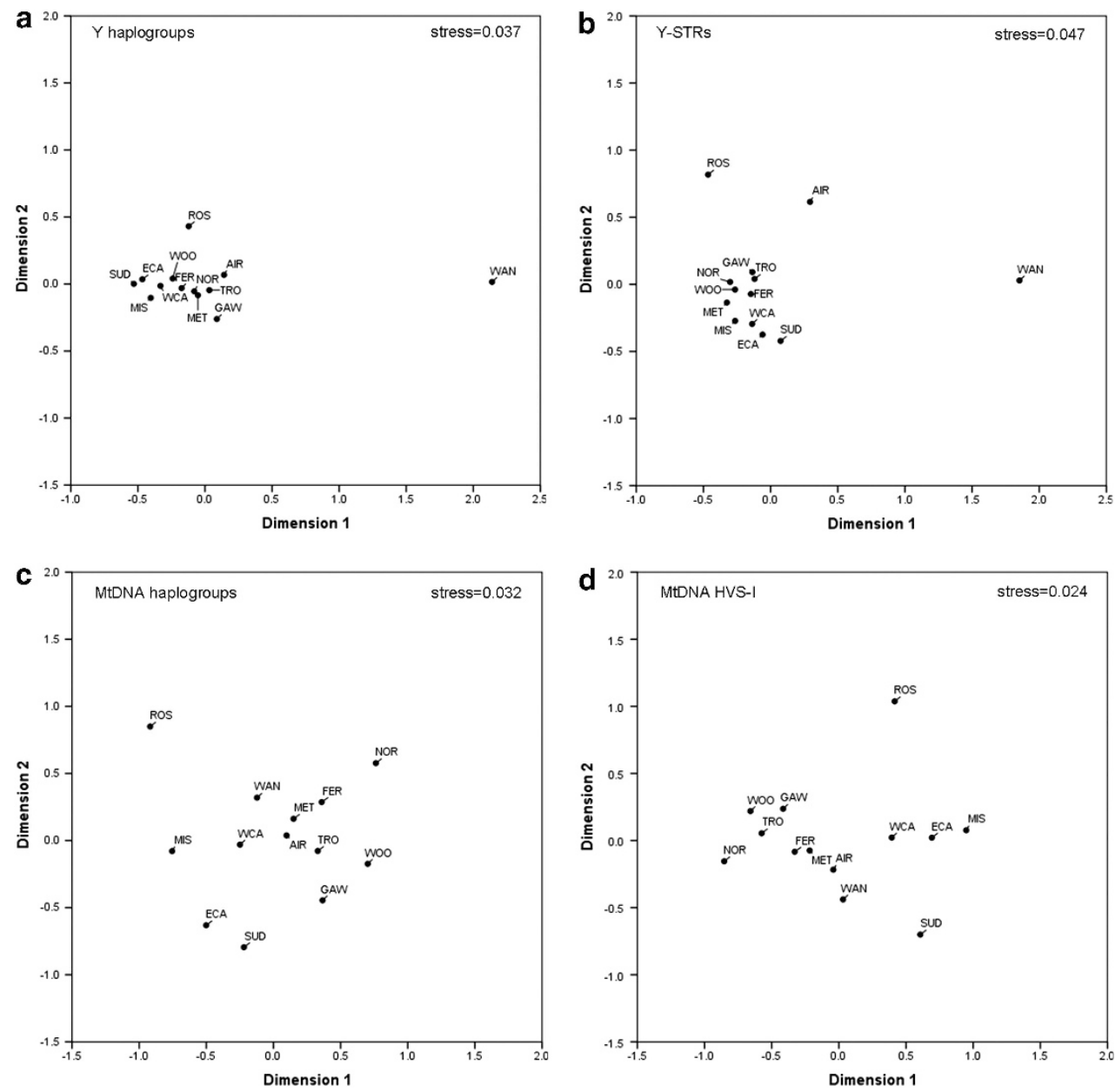

Figure 3 MDS plots of the Massim groups based on (a) $F_{\text {ST }}$ values derived from NRY haplogroups, (b) $R_{\text {ST }}$ values derived from Y-STR haplotypes, (c) $F_{S T}$ values derived from mtDNA haplogroups and (d) $\Phi_{\mathrm{ST}}$ values derived from mtDNA HVS-I haplotypes. The Laughlan Islands sample was not included in this analysis because of its small sample size $(n<10)$.

Table 4 Pairwise number of shared haplotypes between sampled groups of the Massim area for Y-STRs (below the diagonal) and mtDNA HVS-I (above the diagonal)

\begin{tabular}{|c|c|c|c|c|c|c|c|c|c|c|c|c|c|c|c|}
\hline & & WAN & $A / R$ & FER & NOR & MET & TRO & GAW & WOO & $\angle A U$ & MIS & $W C A$ & $E C A$ & SUD & $R O S$ \\
\hline WAN & 12 & - & 2 & 1 & 1 & 3 & 1 & 1 & 1 & 1 & 2 & 1 & & 1 & 1 \\
\hline FER & 25 & & & - & 4 & 4 & 6 & 3 & 3 & 3 & 2 & 1 & 2 & 4 & 4 \\
\hline NOR & 25 & & & 7 & - & 3 & 2 & 1 & 1 & 1 & 3 & 2 & 2 & 3 & 1 \\
\hline MET & 19 & & & & 1 & - & 4 & 2 & 3 & 2 & 4 & 3 & 2 & 2 & 3 \\
\hline WOO & 9 & & & 3 & 4 & & 1 & 1 & - & 3 & 1 & & 1 & 2 & 2 \\
\hline LAU & 5 & & & & & 1 & & 1 & & - & 1 & & & 2 & 2 \\
\hline MIS & 14 & & & 2 & & 1 & 3 & & & & - & 4 & 2 & 2 & 1 \\
\hline WCA & 19 & & & 4 & 6 & & 2 & & 3 & 1 & 2 & - & 3 & 1 & \\
\hline ECA & 10 & & & 1 & 1 & & & & 1 & 1 & & 2 & - & 4 & 1 \\
\hline
\end{tabular}

For population sample abbreviations, see Table 1.

The total number of observed haplotypes in each group is shown left of the matrix for Y-STR haplotypes and above the matrix for mtDNA HVS-I haplotypes, both in italic. 

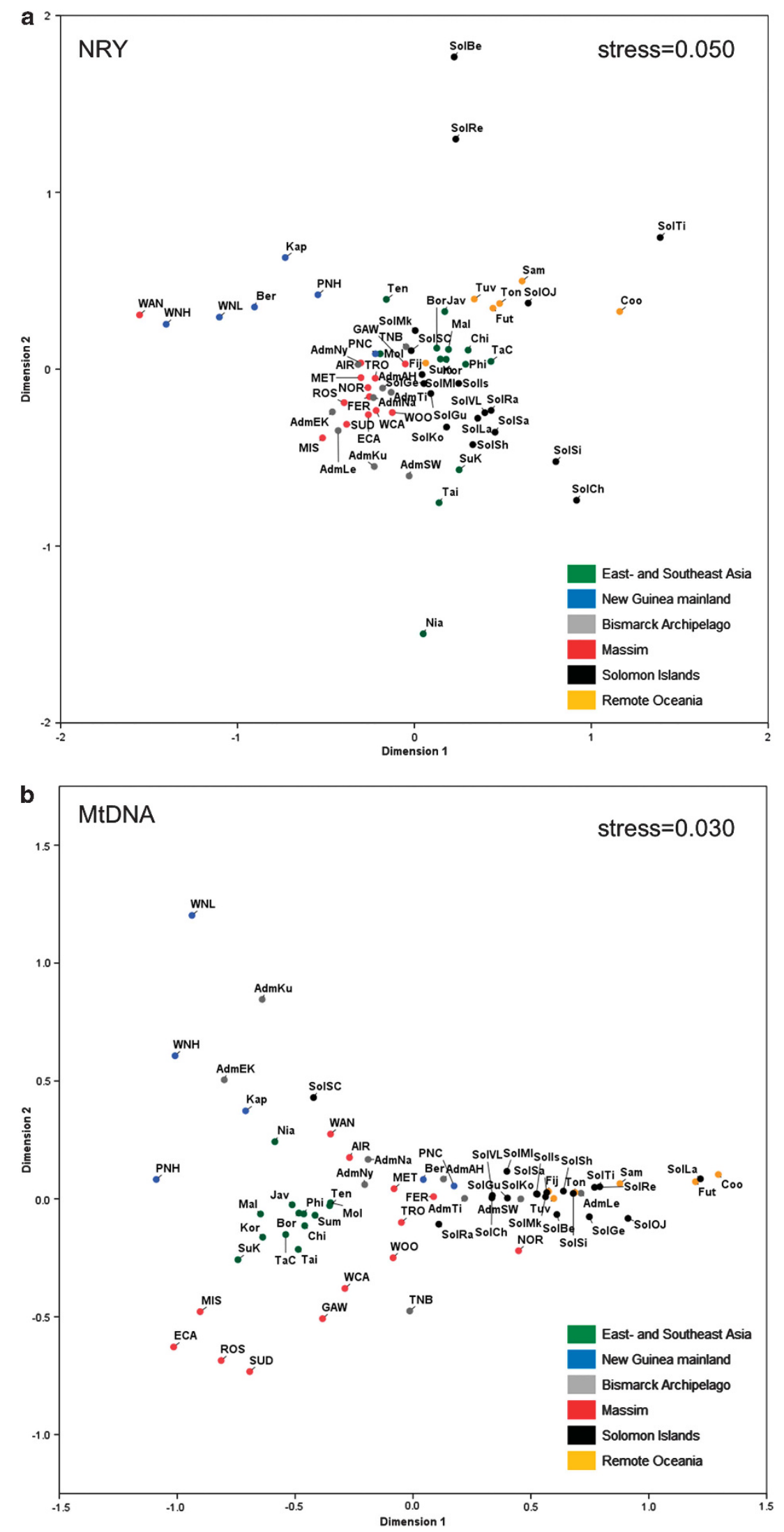
that genetic exchange between these groups was rather limited. The other genetic outlier particularly for Y-STR and mtDNA haplotypes (less so for NRY/mtDNA haplogroups) is Rossel (Figure 3) (for further details on Rossel see below).

Apart from the outliers, the positioning of the sampled groups is in good agreement with geography. When we repeated the MDS analysis without the Airara, Wanigela and Rossel groups (Supplementary Figure S2), a strong north-south correlation with geography along the first dimension was seen in all four plots. Notably, Seligmann ${ }^{21}$ and Malinowksi ${ }^{33}$ had provisionally subdivided the Massim-on ethnographic grounds-into a northern and a southern portion. We considered and tested several alternative subdivisions by means of AMOVA, while leaving out Wanigela and Airara for the reason explained above (Supplementary Table S7). The grouping that explained the largest proportion of among-group variation for both NRY and mtDNA data was a division into three groups: (1) the western plus northern Massim, (2) the southeastern Massim excluding Rossel and (3) Rossel. This grouping explained 15.98\% $(P<0.001)$ of the among-group variation for mtDNA haplotypes, $14.78 \%(P<0.001)$ for mtDNA haplogroups, $10.18 \%(P<0.001)$ for Y-STR haplotypes and 7.91\% $(P<0.001)$ for NRY haplogroups.

When performing an AMOVA with the whole Massim as one group (again excluding Wanigela and Airara), the among-populations percentage was $6.47 \%(P<0.001)$ for NRY haplogroups and $7.37 \%$ $(P<0.001)$ for Y-STR haplotypes, whereas for mtDNA haplogroups and haplotypes this was $17.99 \%(P<0.001)$ and $18.33 \%(P<0.001)$, respectively. Although the Massim Y-STR value $(7.37 \%)$ is lower than that obtained for the Admiralties (10.31\%) and Solomons (ex-Polynesian outliers) (11.09\%), the Massim mtDNA haplotype value $(18.33 \%)$ is high compared with that of the Admiralties (12.3\%) and Solomons (ex-Polynesian outliers) (13.1\%) (Supplementary Table S8). This comparative result suggests that the Massim are more structured mtDNA-wise than NRY-wise, and more so than other regions of NO studied so far.

We furthermore investigated the putative effect of the Kula trading system on genetic population substructure of the Massim. As the Kula trade occurs between islands in a circular manner in both clockwise and counter-clockwise direction depending on the objects traded, we modeled the Kula system as a ring of participating trading partners that can exchange goods with adjacent partners (Figure 1). Notably, however, not all Massim islands participate in the Kula. From the populations included in this study, the Calvados chain islands, Sudest and Rossel as well as the PNG mainland populations of Airara and Wanigela are not known to be involved in the Kula ${ }^{33}$ and were therefore excluded from the model. Furthermore, the Laughlan Islanders, who may be only marginally involved in the Kula, ${ }^{37}$ were excluded because of small sample size. Genetic distances appropriate for the marker type (Supplementary Table S6) were compared via Mantel testing with circular trading distances. For NRY (both at the haplogroup level and at the haplotype level) no statistically significant correlation was observed, whereas for mtDNA a significant correlation was observed both for haplotype data $(0.42 ; P=0.029)$ and for haplogroup data $(0.47 ; P=0.019)$. This result can be explained by predominantly male-mediated gene flow between islands involved in the Kula, having a homogenizing effect on the Y-chromosome diversity but not on the mtDNA pool. As only men traditionally participate in the Kula voyages, this finding may indicate a genetic signature of the Kula Ring. However, the mtDNA-based correlation decreased and became nonsignificant when excluding Misima, which is reported to be less intensively involved in the Kula. ${ }^{35,38}$

\section{Genetic characterization of Rossel Islanders}

Rossel Islanders, who live on the easternmost and most remote island of the entire Massim, occupy a unique position within the Massim because they are its only Papuan-speaking people. Their outlier position as noted above, despite their geographic proximity to Austronesian-speaking neighboring islanders from the southeastern Massim, is therefore intriguing. It is also remarkable that Rossel Islanders are characterized by a larger proportion of haplogroups of AS origin than all other groups from the southeastern Massim (Table 3), although all these other groups speak Austronesian languages. Haplotype network analyses for the major NRY (O-M110 and S-M254*) and mtDNA haplogroups (P1 and $\mathrm{E}^{*}$ ) found in Rossel (Supplementary Figure S3) revealed some degree of haplotype sharing between Rossel Islanders and other groups of the southeastern Massim, in particular for the NO haplogroups S-M254* and P1, suggesting a shared southeastern Massim ancestry for at least the NO component. When and from where the strong AS ancestry component was contributed to Rossel's gene pool cannot be answered precisely, but it is noteworthy that while all AS NRY haplogroups found on Rossel also occur on other southeastern Massim islands, this is not the case for AS mtDNA haplogroups found on Rossel, which therefore were most likely contributed from elsewhere, perhaps from the northern Massim. Although this finding may indicate that Rossel Islanders have sex-biased local ancestry differences within the Massim, our genetic data do not reveal the exceptional outlier position of Rossel that is expected from linguistic data.

\section{The Massim relationships to other populations}

A comparison of the Massim data with reference data from other populations of Asia/Oceania (Figure 2) highlights the Admiralty Islands of Northern Melanesia and the PNG Coast as the most similar reference populations to the Massim in terms of overall haplogroup composition. Interestingly, the Massim appear to be quite different from the geographically closer Solomon Islanders. Concerning NRY, the Solomon Islanders harbor more diverse NRY lineages than the Massim; for example, several C, K, M and O lineages present in the Solomon Islanders ${ }^{18}$ are absent from our Massim sample, but are also found in the Bismarck Archipelago. ${ }^{14}$ Similarly for mtDNA, the Northern Melanesian lineages M27 and M28 are found in the Solomons ${ }^{18}$ and in the Bismarcks, ${ }^{15}$ but not in our Massim sample. Thus, it is likely that there were direct links between the Bismarcks and the Solomons that bypassed the Massim region.

To further investigate the relationships of the Massim people in the wider context of East and Southeast Asia and Near- and Remote

Figure 4 MDS plots of regional populations based on (a) $F_{\mathrm{ST}}$ values derived from NRY haplogroups and (b) $F_{\mathrm{ST}}$ values derived from mtDNA haplogroups. Only populations with a sample size of 10 or larger (for both NRY and mtDNA) were included. Population abbreviations are as in Supplementary Table S1. The Admiralty ${ }^{16}$ and Solomon Islands ${ }^{18}$ populations are indicated by Adm and Sol, respectively, followed by another abbreviation indicating the sub-population, as follows for the Admiralty Islands: AH, Andra-Hus; EK, Ere Kele; Ku, Kurti; Le, Lele; Mo, Mokerang; Na, Nali; Ni, Nyindrou; SW, Seimat-Wuvulu; Ti, Titan; and for the Solomon Islands: Be, Bellona; Ch, Choiseul; Ge, Gela; Gu, Guadalcanal; Is, Isabel; Ko, Kolombangara; La, Lavukaleve; Mk, Makira; MI, Malaita, OJ, Ontong Java; Ra, Ranongga; Re, Rennell; Sa, Savo; SC, Santa Cruz; Sh, Shortlands; Si, Simbo; Ti, Tikopia; VL, Vella Lavella. 
Oceania, MDS plots were constructed based on NRY and mtDNA haplogroup frequencies using all regional population data available (Figure 4). In both plots, the positioning of the populations is in agreement with geography. In the NRY plot, the Massim groups appear close to the Austronesian-speaking Admiralty Island groups, in line with the hypothesis that Austronesian ancestors from East/ Southeast Asia came to NO via the Bismarck Archipelago and from there occupied other parts of NO such as the Massim, as well as Remote Oceania. ${ }^{16}$ Wanigela, however, is distinct (consistent with Figure 3), being closest to the Western New Guinea highlands population to which it is very similar in NRY haplogroup composition. For mtDNA, the Massim groups appear much more dispersed, consistent with the observation that the Massim are more structured with respect to mtDNA than to NRY.

\section{CONCLUSIONS}

We genetically characterized, for the first time, the people of the Massim, thereby filling another gap in the complex human genetic history of NO. We found that the nearly exclusively Austronesianspeaking Massim harbor components of both AS (Austronesian) and NO (Papuan) origin with proportionally more NO Y-chromosomes and more AS mtDNAs, similar to previous observations in Austronesian-speaking groups from the Admiralty Islands north of mainland PNG, ${ }^{16}$ the Solomon Islands ${ }^{18}$ and Polynesia, ${ }^{7}$ and in line with the Slow Boat from Asia hypothesis on Austronesian dispersal. ${ }^{4}$ MtDNAwise, the Massim appear more structured than populations from nearby regions such as the Admiralty Islands ${ }^{16}$ and the Solomon Islands. ${ }^{18}$ Both NRY and mtDNA data best support a broad three-way division of the Massim into a northwestern group, a southeastern group (excluding Rossel) and Rossel, with larger differentiation in mtDNA than in NRY. The Rossel Islanders, the only non-Austronesian (ie, Papuan) speaking people within the Massim, occupy an outlier position when compared with the other Massim groups studied, probably as a result of isolation and genetic drift. Surprisingly, however, Rossel Islanders exhibited a lower NO and higher AS (Austronesian) contribution for both NRY and mtDNA than their geographic neighbors from the southeastern Massim who speak Austronesian languages. Considering those Massim populations that participate in the Kula traditional trading system, a correlation between inter-island trading distances and genetic distances was detected for mtDNA but not for the Y-chromosome, which can be explained by male-mediated but not female-mediated gene flow throughout the Kula region. As only men participate in Kula trading, this may be a genetic signature of the Kula in contemporary inhabitants of the region. Our study thus provides insights into how a social trading system can impact on human genetic diversity, representing another example of the interplay between culture and genes, in addition to residence pattern (patrilocality versus matrilocality) ${ }^{39}$ and social stratification. ${ }^{40}$ Finally, we would like to emphasize the particular suitability of studying the uni-parentally inherited genetic systems NRY and mtDNA for investigating those parts of human genetic history that are influenced by males and females differently, such as sex-biased migrations as studied here with the Kula, and for which bi-parentally inherited genetic diversity as obtained via genome-wide SNP data is much less useful.

\section{CONFLICT OF INTEREST}

The authors declare no conflict of interest.

\section{ACKNOWLEDGEMENTS}

We thank all DNA donors who participated in this study. In addition, we are grateful to representatives of the Diocese of Alotau, PNG (MSC), particularly then Bishop Desmond Moore MSC; the entire crew of the Morning Star (particularly then Captain Pius) for infrastructural support in collecting samples; and all the people from the various islands who made our stay pleasant. Furthermore, we thank Oscar Lao for statistical advice, and Michael Dunn, Ger Reesink, Fiona Jordan and Gunter Senft for useful discussions regarding cultural and linguistic aspects. This work was supported by the Max Planck Society and by the Erasmus MC University Medical Center Rotterdam.

1 Hurles ME, Matisoo-Smith E, Gray RD, Penny D: Untangling Oceanic settlement: the edge of the knowable. Trends Ecol Evol 2003; 18: 531-540.

2 Kayser M: The human genetic history of Oceania: near and remote views of dispersal. Curr Biol 2010; 20: R194-R201.

3 Sykes B, Leiboff A, Low-Beer J, Tetzner S, Richards M: The origins of the Polynesians: an interpretation from mitochondrial lineage analysis. Am J Hum Genet 1995; 57: 1463-1475.

4 Kayser M, Brauer S, Weiss G et al: Melanesian origin of Polynesian Y chromosomes. Curr Biol 2000; 10: 1237-1246.

5 Su B, Jin L, Underhill $P$ et al: Polynesian origins: insights from the $Y$ chromosome. Proc Natl Acad Sci U S A 2000; 97: 8225-8228.

6 Hurles ME, Nicholson J, Bosch E, Renfrew C, Sykes BC, Jobling MA: Y chromosoma evidence for the origins of Oceanic-speaking peoples. Genetics 2002; 160 289-303.

7 Kayser M, Brauer S, Cordaux R et al: Melanesian and Asian origins of Polynesians: mtDNA and Y chromosome gradients across the Pacific. Mol Biol Evol 2006; 23 2234-2244

8 Soares P, Rito T, Trejaut J et al: Ancient voyaging and Polynesian origins. Am J Hum Genet 2011; 88: 239-247.

9 Stoneking $\mathrm{M}$, Jorde LB, Bhatia K, Wilson AC: Geographic variation in human mitochondrial DNA from Papua New Guinea. Genetics 1990; 124: 717-733

10 Tommaseo-Ponzetta M, Attimonelli M, De Robertis M, Tanzariello F, Saccone C: Mitochondrial DNA variability of West New Guinea populations. Am J Phys Anthropol 2002; 117: 49-67.

11 Kayser M, Brauer S, Weiss G et al: Reduced Y-chromosome, but not mitochondrial DNA, diversity in human populations from West New Guinea. Am J Hum Genet 2003; 72: 281-302.

12 Mona S, Tommaseo-Ponzetta M, Brauer S, Sudoyo H, Marzuki S, Kayser M: Patterns of Y-chromosome diversity intersect with the Trans-New Guinea hypothesis. Mol Biol Evol 2007: 24: 2546-2555.

13 Vilar MG, Kaneko A, Hombhanje FW, Tsukahara T, Hwaihwanje I, Lum JK: Reconstructing the origin of the Lapita Cultural Complex: mtDNA analyses of East Sepik Province, PNG. J Hum Genet 2008; 53: 698-708.

14 Scheinfeldt L, Friedlaender F, Friedlaender J et al: Unexpected NRY chromosome variation in Northern Island Melanesia. Mol Biol Evol 2006; 23: 1628-1641.

15 Friedlaender JS, Friedlaender FR, Hodgson JA et al: Melanesian mtDNA complexity. PloS One 2007; 2: e248.

16 Kayser M, Choi $\mathrm{Y}$, van Oven $\mathrm{M}$ et al: The impact of the Austronesian expansion: evidence from mtDNA and $Y$ chromosome diversity in the Admiralty Islands of Melanesia. Mol Biol Evol 2008; 25: 1362-1374.

17 Cox MP, Mirazón Lahr M: Y-chromosome diversity is inversely associated with language affiliation in paired Austronesian- and Papuan-speaking communities from Solomon Islands. Am J Hum Biol 2006; 18: 35-50.

18 Delfin F, Myles S, Choi $Y$ et al: Bridging near and remote Oceania: mtDNA and NRY variation in the Solomon Islands. Mol Biol Evol 2012; 29: 545-564.

19 Hamy ET: Étude sur les Papouas de la mer d'Entrecasteaux. Rev Ethnogr 1888; 7 503-519.

20 Haddon AC: The Decorative Art of British New Guinea: A Study in Papuan Ethnography. Dublin: Academy House, 1894

21 Seligmann CG: A classification of the natives of British New Guinea. J R Anthropol Inst G B Irel 1909; 39. 246-275.

22 Young MW: The Massim: an introduction. J Pac Hist 1983; 18: 4-10.

23 Lum JK, Jorde LB, Schiefenhovel W: Affinities among Melanesians, Micronesians, and Polynesians: a neutral biparental genetic perspective. Hum Biol 2002; 74 413-430.

24 Summerhayes GR, Leavesley M, Fairbairn A et al: Human adaptation and plant use in highland New Guinea 49,000 to 44,000 years ago. Science 2010; 330: 78-81.

25 Wickler S, Spriggs M: Pleistocene human occupation of the Solomon Islands, Melanesia. Antiquity 1988; 62: 703-706.

26 Kirch PV: Prehistoric exchange in western Melanesia. Annu Rev Anthropol 1991; 20 141-165.

27 Irwin G: Themes in the prehistory of coastal Papua and the Massim; in Pawley A (ed) Man and a Half: Essays in Pacific Anthropology and Ethnobiology in Honour of Ralf Bulmer. Auckland: The Polynesian Society, 1991; pp 503-510.

28 Bickler SH: Prehistoric stone monuments in the northern region of the Kula Ring. Antiquity 2006; 80: 38-51. 
29 Voris HK: Maps of Pleistocene sea levels in Southeast Asia: shorelines, river systems and time durations. J Biogeogr 2000; 27: 1153-1167.

30 Ross M: Proto Oceanic and the Austronesian Languages of Western Melanesia. Canberra: Australian National University, 1988.

31 Henderson JA: Yeletnye, the language of Rossel Island; in Dutton TE (ed) Studies in the Languages of Central and South-East Papua. Pacific Linguistics. Canberra: Australian National University, 1975; pp 817-834.

32 Malinowski B: Kula; the circulating exchange of valuables in the archipelagoes of eastern New Guinea. Man 1920; 20: 97-105.

33 Malinowksi B: Argonauts of the Western Pacific; An Account of Native Enterprise and Adventure in the Archipelagoes of Melanesian New Guinea, 1978 reprint editionLondon and Henley: Routledge \& Kegan Paul, 1922.

34 Landa JT: The enigma of the Kula Ring: gift-exchanges and primitive law and order. Int Rev Law Econ 1983; 3: 137-160.

35 Leach J, Leach E: The Kula: New Perspectives on Massim Exchange. Cambridge: Cambridge University Press, 1983.

36 Macintyre M: The Kula: A Bibliography. Cambridge: Cambridge University Press, 1983.

37 Ziegler R: The Kula Ring of Bronislaw Malinowski: co-evolution of an economic and ceremonial exchange system. Rev Eur Stud 2012; 4: 15-27.

38 Rynkiewich MA: The world in my parish: rethinking the standard missiological model. Missiology 2002; 30: 301.

39 Oota H, Settheetham-Ishida W, Tiwawech D, Ishida T, Stoneking M: Human mtDNA and Y-chromosome variation is correlated with matrilocal versus patrilocal residence. Nat Genet 2001; 29: 20-21.

40 Pemberton TJ, Li F-Y, Hanson EK et al: Impact of restricted marital practices on genetic variation in an endogamous Gujarati group. Am J Phys Anthropol 2012; 149: 92-103.

41 Armstrong WE: Rossel Island: An Ethnological Study. Cambridge: Cambridge University Press, 1928.

42 Mona S, Grunz KE, Brauer S et al: Genetic admixture history of Eastern Indonesia as revealed by Y-chromosome and mitochondrial DNA analysis. Mol Biol Evol 2009; 26: 1865-1877.

43 van Oven M, Hämmerle JM, van Schoor M et al: Unexpected island effects at an extreme: reduced $Y$ chromosome and mitochondrial DNA diversity in Nias. $\mathrm{Mol}$ Biol Evol 2011; 28: 1349-1361.

44 Miller SA, Dykes DD, Polesky HF: A simple salting out procedure for extracting DNA from human nucleated cells. Nucleic Acids Res 1988; 16: 1215.

45 Ballantyne $\mathrm{KN}$, van Oven M, Ralf $\mathrm{A}$ et al: MtDNA SNP multiplexes for efficient inference of matrilineal genetic ancestry within Oceania. Forensic Sci Int Genet 2012; 6: $425-436$
46 Karafet TM, Mendez FL, Meilerman MB, Underhill PA, Zegura SL, Hammer MF: New binary polymorphisms reshape and increase resolution of the human $Y$ chromosomal haplogroup tree. Genome Res 2008; 18: 830-838.

47 van Oven M, Kayser M: Updated comprehensive phylogenetic tree of global human mitochondrial DNA variation. Hum Mutat 2009; 30: E386-E394.

48 Excoffier L, Lischer HEL: Arlequin suite ver 3.5: a new series of programs to perform population genetics analyses under Linux and Windows. Mol Ecol Resour 2010; 10 : 564-567.

49 Busing FMTA, Commandeur JJF, Heiser WJ: PROXSCAL: a multidimensional scaling program for individual differences scaling with constraints; in Bandilla W, Faulbaum $\mathrm{F}$ (eds) SoftStat '97: Advances in Statistical Software 6. Stuttgart: Lucius \& Lucius, 1997; pp 67-74.

50 Bandelt HJ, Forster P, Röhl A: Median-joining networks for inferring intraspecific phylogenies. Mol Biol Evol 1999; 16: 37-48.

51 Kong Q-P, Yao Y-G, Sun C, Bandelt H-J, Zhu C-L, Zhang Y-P: Phylogeny of East Asian mitochondrial DNA lineages inferred from complete sequences. Am J Hum Genet 2003; 73: 671-676.

52 Trejaut JA, Kivisild T, Loo JH et al: Traces of archaic mitochondrial lineages persist in Austronesian-speaking Formosan populations. PLoS Biol 2005; 3: e247.

53 Melton T, Peterson R, Redd AJ et al: Polynesian genetic affinities with Southeast Asian populations as identified by mtDNA analysis. Am J Hum Genet 1995; 57: 403-414.

54 Redd AJ, Takezaki N, Sherry ST, McGarvey ST, Sofro AS, Stoneking M: Evolutionary history of the COII/tRNALys intergenic 9 base pair deletion in human mitochondrial DNAs from the Pacific. Mol Biol Evol 1995; 12: 604-615.

55 Richards M, Oppenheimer S, Sykes B: MtDNA suggests Polynesian origins in Eastern Indonesia. Am J Hum Genet 1998; 63: 1234-1236.

56 Soares P, Trejaut JA, Loo J-H et al: Climate change and postglacial human dispersals in southeast Asia. Mol Biol Evol 2008; 25: 1209-1218.

57 Friedlaender J, Schurr T, Gentz F et al: Expanding Southwest Pacific mitochondrial haplogroups P and Q. Mol Biol Evol 2005; 22: 1506-1517.

58 Hill C, Soares P, Mormina M et al: A mitochondrial stratigraphy for Island Southeast Asia. Am J Hum Genet 2007; 80: 29-43.

59 Peng M-S, Quang HH, Dang KP et al: Tracing the Austronesian footprint in Mainland Southeast Asia: a perspective from mitochondrial DNA. Mol Biol Evol 2010; 27: 2417-2430

60 Wollstein A, Lao O, Becker C et al: Demographic history of Oceania inferred from genome-wide data. Curr Biol CB 2010; 20: 1983-1992.

61 Key CA: Pottery manufacture in the Wanigela area of Collingwood Bay, Papua. Mankind 2009; 6: 653-657.

62 Egloff BJ: The Kula before Malinowski: a changing configuration. Mankind 2010; 11: $429-435$.

Supplementary Information accompanies this paper on European Journal of Human Genetics website (http://www.nature.com/ejhg) 